\title{
Meeting the family planning needs of postpartum women
}

Ricardo Vernon

Follow this and additional works at: https://knowledgecommons.popcouncil.org/departments_sbsr-rh

Part of the Demography, Population, and Ecology Commons, Family, Life Course, and Society Commons, Gender and Sexuality Commons, International Public Health Commons, Maternal and Child Health Commons, Medicine and Health Commons, and the Women's Health Commons How does access to this work benefit you? Let us know!

\section{Recommended Citation}

Vernon, Ricardo. 2008. "Meeting the family planning needs of postpartum women," FRONTIERS Program Brief. Washington, DC: Population Council. 


\section{Meeting the Family Planning Needs of Postpartum Women}

$T$ he first days, weeks, and months after a delivery represent a period of substantial information and service needs for both mother and child, including treatment of hemorrhage and infections, breastfeeding information and support, nutritional complements and micronutrients, immunizations for children and mothers, counseling for managing intimate partner violence and depression, and, most importantly, contraception. In areas of high HIV prevalence, contraceptives and antiretroviral therapy are especially critical elements of postpartum care.

Yet despite its strategic importance, few organizations have made it a priority to address women's reproductive health and fertility needs during the year following delivery. The situation is compounded by the scarcity of postpartum care in many countries, creating a major public health concern (Fort, Kothari, and Abderrahim 2006).

This Program Brief focuses on the degree to which service delivery organizations in sub-Saharan Africa, Asia and the Near East, and Latin America and the Caribbean (LAC) meet the contraceptive needs of women in the postpartum period and the strategies they have tested for doing so. The brief principally relies on reviewing the results and lessons learned from operations research (OR) projects conducted by the Population Council's Frontiers in Reproductive Health Program (FRONTIERS).

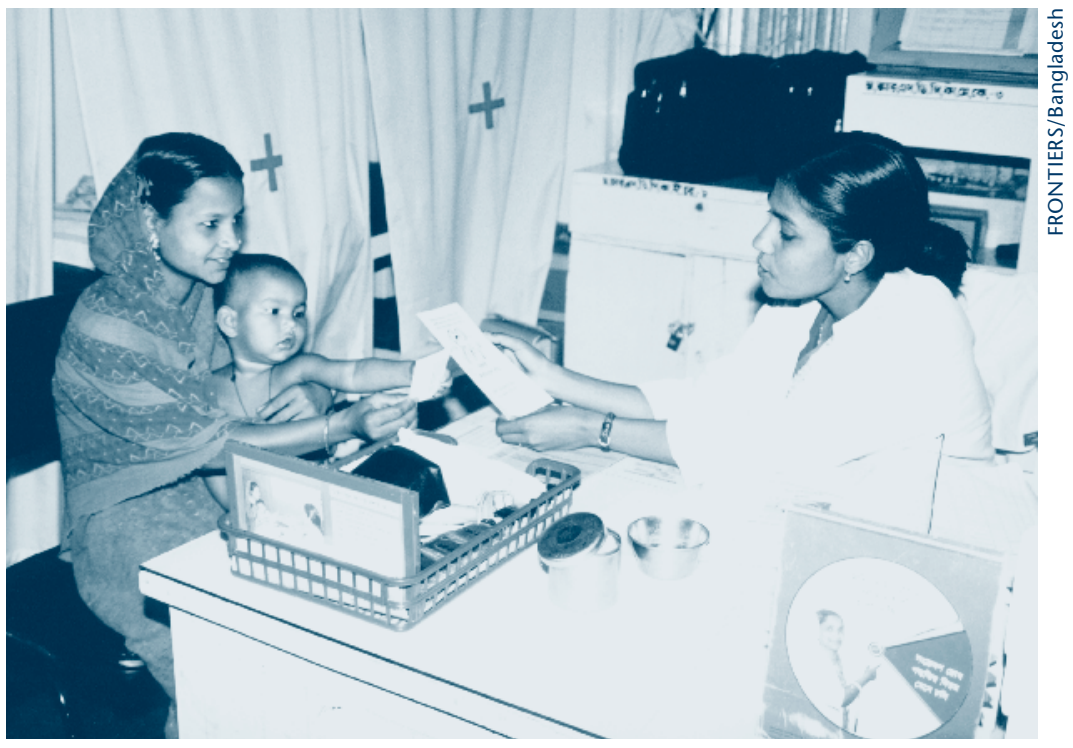

Women need family planning information and services in the postpartum period.

- Postpartum contraception offers benefits to women, children, and health systems.

Women need information and services, including a range of family planning methods, throughout the maternal cycle, including the postpartum period.

Research has identified many approaches for improving access to postpartum family planning methods.

- Postpartum family planning can be integrated into other programs, including programs to prevent and manage HIV. 


\section{Frontiers in Reproductive Health} Program Brief No. 10

Author: Ricardo Vernon

Editor: Stephanie Joyce

Design: Vincent Hughes Visualization

The assistance and contributions of the following reviewers is appreciated: Nahla Abdel-Tawab, Marcos Arévalo, Ian Askew, M.E. Khan, Laura Raney, Estela Rivero-Fuentes, Catharine McKaig, Patricia Stephenson, John Townsend, and Charlotte Warren.

Suggested citation: Vernon, Ricardo. 2008. "Meeting the Family Planning Needs of Postpartum Women," FRONTIERS Program Brief No. 10. Washington, DC: Population Council.

The Frontiers in Reproductive Health Program (FRONTIERS) applies systematic research techniques to improve delivery of family planning and reproductive health services and influence related policies. FRONTIERS is funded by the U. S. Agency for International Development (USAID) and led by the Population Council in collaboration with Family Health International.

This publication is made possible by the generous support of the American people through the United States Agency for International Development (USAID) under the terms of Cooperative Agreement No. HRN-A-00-98-00012-00. The contents are the responsibility of the FRONTIERS Program and do not necessarily reflect the views of USAID or the United States Government.

(C) 2008 The Population Council, Inc.

This publication may be reproduced in whole or in part without permission of the Population Council provided full source citation is given and the reproduction is not for commercial purposes.

ISSN 1546-6612

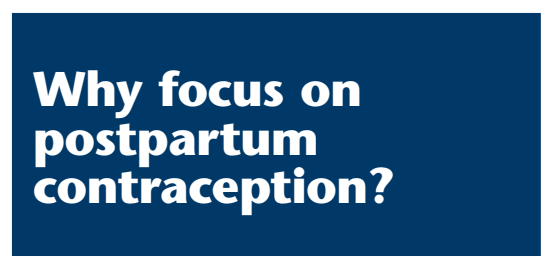

Postpartum contraceptive programs are strategically important from a public health perspective, with significant benefits to women and their children. Integrating contraception can benefit health systems as well by increasing women's use of postpartum, well-baby, family planning, and other services.

\section{Reducing mortality}

Ross and Winfrey (2001) show that in 27 less developed countries, two-thirds of women within a year of their last delivery have an unmet need for contraception and that nearly 40 percent plan to use a method but have not done so. Other studies showed that between 25 percent and 40 percent of maternal deaths could be eliminated if unplanned and unwanted pregnancies were prevented (Campbell and Graham 2006), and that 10 percent of child deaths could be avoided if all new pregnancies were spaced at least two years after a birth (Cleland et al. 2006). Postpartum contraception is especially important in areas of high HIV prevalence; Reynolds and Wilcher (2006) describe the prevention of unintended pregnancies for HIV-positive women as an undervalued and littleused strategy for preventing
HIV-positive births. Thus, many lives could be saved if programs met women's family planning needs during the postpartum period, especially if programs promote the use of lactational amenorrhea as a means to space births in the first six months, given that full breastfeeding is associated with lower infant mortality (León-Cava, Lutter, Ross, and Martin 2002).

\section{Increasing contraceptive use}

OR studies have shown that making contraceptive methods available in the postpartum period leads to higher contraceptive prevalence rates. A study in Peru compared a cohort of women who were offered counseling and temporary methods, including the intrauterine device (IUD), in one ward at a hospital in Peru with a cohort of women in a different ward who were discharged without being offered comparable services. Six months after delivery, 82 percent of the women who were offered methods were using one, with 40 per-

Contents
Why focus on postpartum contraception?
What approaches work?

Approaches with limited success

Ensuring quality in postpartum family planning services

Conclusions 13

References 16 


\section{The postpartum period}

The postpartum period is commonly understood as the first six weeks or 40 days (depending on the culture) after the birth of a child, when the woman's uterus has largely returned to its prepregnancy state. However, programs frequently differentiate this period from the immediate postpartum (the first two to six days after delivery or the period between delivery and the discharge from the hospital) and the extended postpartum period (the first year after delivery). This is when the child needs food other than maternal milk and the mother needs a contraceptive method if she is sexually active and wants to space the next pregnancy.

cent using the IUD. By comparison, 69 percent of women who had not been offered the methods were using one, with 27 percent using an IUD (Foreit, Foreit, Lagos, and Guzman 1993).

\section{Containing program costs}

Providing family planning services in the immediate postpartum period can be more cost-effective than providing them after the six-week post-delivery period. Khan (2003), for example, found that postpartum contraception accounted for only 3 percent of the family welfare budget in India, but made up 19 percent of all sterilizations and 8 percent of all IUD insertions performed. Similarly, Foreit, Foreit, Lagos, and Guzman (1993) found that conducting an IUD insertion before discharge from the hospital cost US\$9.36 per woman, compared to $\$ 24.16$ for an interval (after six weeks postpartum) insertion.

\section{Meeting women's fertility desires}

Research in sub-Saharan Africa, Asia and the Near East, and LAC shows that more than 80 percent of women do not want a pregnancy in the two years following a delivery, including a substantial proportion of women who do not want more children. About half of these women would like to start using a contraceptive method during the postpartum period. Of these, more than half want to begin using a method immediately after delivery or at six weeks; the rest mention a time between six weeks and one year, most often at six months or at what they perceive as the return of fertility (see, for example, Medina, Vernon, Mendoza, and Aguilar 2001; Brambila, Figueroa, and Taracena 2001; Quiterio et al. 2007; Rivero-Fuentes, Vernon, Boulos, and Boulos 2007; Solís et al. 2007; Warren et al. 2008). Thus, programs can respond more fully to their clients' desires and needs by providing information about fertility return and contraceptives at different times during the extended postpartum period.

\section{Barriers to postpartum contraception}

Almost universally, a far greater proportion of women use services for antenatal care, immunization, and well-baby care than postnatal care services. In one project area in Guatemala, for example, 50 percent of pregnant women attended antenatal care and 60 percent of children attended immunization services, but only 15 percent of women attended postnatal care services (Jacobs, Brambila, and Vernon 2002). Several factors contribute to the underutilization of postnatal care:

- Guidelines usually establish a fixed point for postnatal care visits-at 40 days, for example-and services provided to women weeks or months after that point are not registered as postnatal care visits.

- When postpartum women are asked to identify their main concern at this time, most mention the child's health. If they have to choose because of time, economic, or travel constraints, they will choose services for their child (Salway and Nurani 1998; Bulut and Molzan-Turan 1995).

- In many countries, guidelines for the six-week postnatal care visit focus on checking the mother's health but not on meeting reproductive or other health needs. So, if mothers feel well and their children are not sick, they tend to see little reason to visit the clinic.

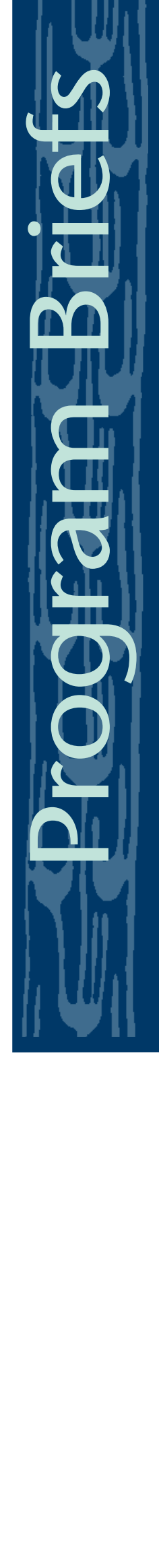


- In countries with established schedules of visits for mothers and children, independent schedules exist for each, requiring mothers to visit the health center several times over a short period to comply with both schedules. This situation raises the cost of care and, given the preference for child visits, acts as a deterrent for women's use of postnatal services.

- Maternal and child health providers often lack knowledge about the return of fertility and lack confidence in their family planning skills.

- Pregnancy checklists rule out amenorrheic women not meeting the lactational amenorrhea method (LAM) criteria although their risk of pregnancy is low.

\section{Types and objectives of postpartum services}

Postpartum contraceptive programs usually seek to provide mothers with contraceptive information and services to help them achieve optimal birth spacing and achieve their fertility goals. Because of the interaction among breastfeeding, the return of menses, and fertility, and because breastfeeding benefits the child, these programs also often provide counseling to encourage exclusive breastfeeding, including LAM, for up to six months and the introduction of complementary foods at this time.

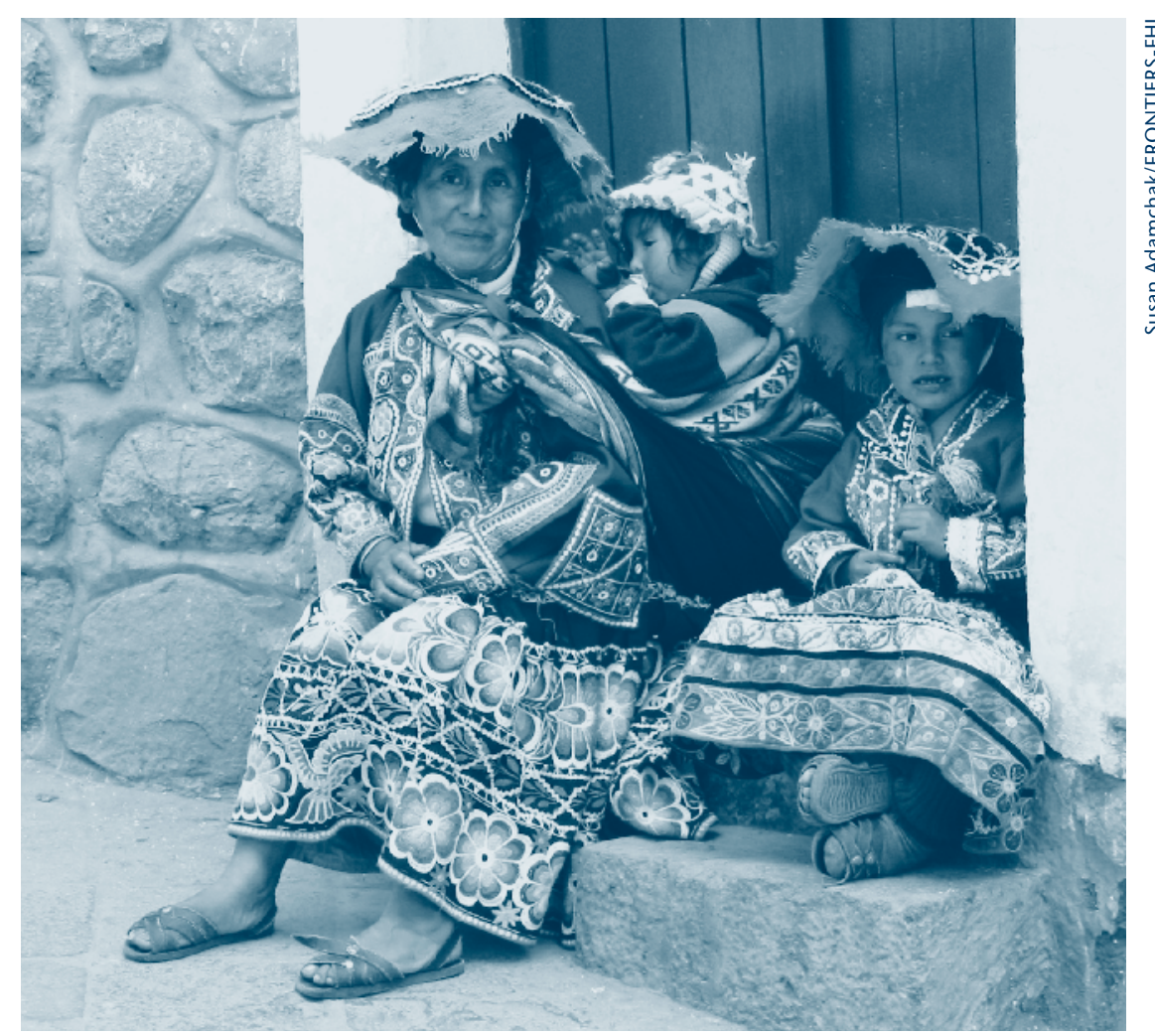

A mother in Peru with her two children.

Integrated postpartum health programs and those providing services for prevention of mother-to-child transmission of HIV (PMTCT) can offer contraception as part of a wider package of care. Providers can deliver postpartum contraceptive services independently at each level of care, or they can link varying levels of care in a more comprehensive program.

Most of the OR studies conducted to date were implemented in hospitals or maternity centers and in outpatient clinics, health centers, and health posts. Only a few projects investigated community-based approaches to meet the needs of women who have no regular contact with formal health services, even though these women have a great need for services.
Studies within the formal health care system focused on three contact points: during antenatal care, in the hospital following delivery, and during visits to outpatient clinics for any reason (including postnatal care, well-baby care, and immunization) for up to 12 months postdelivery. Key outcome indicators included use of outpatient services, use of exclusive breastfeeding or LAM, and acceptance of family planning methods. 
In intervention studies where additional methods are offered to postpartum women, an increase in the uptake of contraception is apparent with each method added (Vernon, Lopez-Canales, Cárcamo, and Galindo 1993). Even when an increase in contraceptive use is not observed, programs are better able to meet the individual needs of their clients. The Honduran Social Security Institute, for example, introduced the IUD in addition to female sterilization services. Although the proportion of women accepting a method at the hospital remained at 9 percent, the method mix changed from a 100 percent reliance on sterilization to a 50-50 percent method mix of sterilization and IUDs (Cárcamo, López-Canales, Murray, and Townsend 1990). Likewise, when information on vasectomy was given to Guatemalan women following a delivery, some couples who wanted a permanent method chose vasectomy over female sterilization (Vernon, Solórzano, and Muñoz 2007).

A corollary to this lesson is that hospitals and maternity centers should seek to provide all methods in the inpatient area. However, administrative barriers require some programs to refer women to outpatient services. In this case, functional guidelines for the referral should be established. In the Dominican Republic, women attending hospitals and maternity centers are referred to outpatient services if they want methods other than sterilization. However, discharge from the hospital often takes place at a time when outpatient family planning services are closed, so many women must return to the clinic another day to receive a method (Quiterio et al. 2007). In Nicaragua, in hospitals where no methods are provided in the inpatient area, only 15 percent of women leave the hospital with a method, compared with 71 percent of women in hospitals that offer sterilization and at least one temporary method following delivery (Solís et al. 2007).

\section{Focus specifically on post- partum contraception}

In Honduras, the research team conducted small quarterly surveys to collect data on five subgroups of women who delivered in hospitals: (1) the proportion who had been given information or counseling on contraception,
(2) those who were offered a method, (3) those who received a method, (4) those who wanted a method but had not received it (called "unmet demand"), and, as a proxy for the quality of services, (5) those who had not received a desired method and had not been given an explanation for this. During a 15-month period, the proportion of women who received family planning information more than doubled, and the proportion who received a method tripled (see Figure 1). The intervention significantly decreased unmet demand for contraception and the proportion of women who were not told why they did not receive a method they wanted (Medina, Vernon, Mendoza, and Aguilar 2001).

Increasing the information provided on the methods available following delivery has a strong influence on women's decisions to use family planning. Figure 2

Figure 1.

\section{Percentage of women in Honduras receiving FP information and methods, pre- and post-intervention}

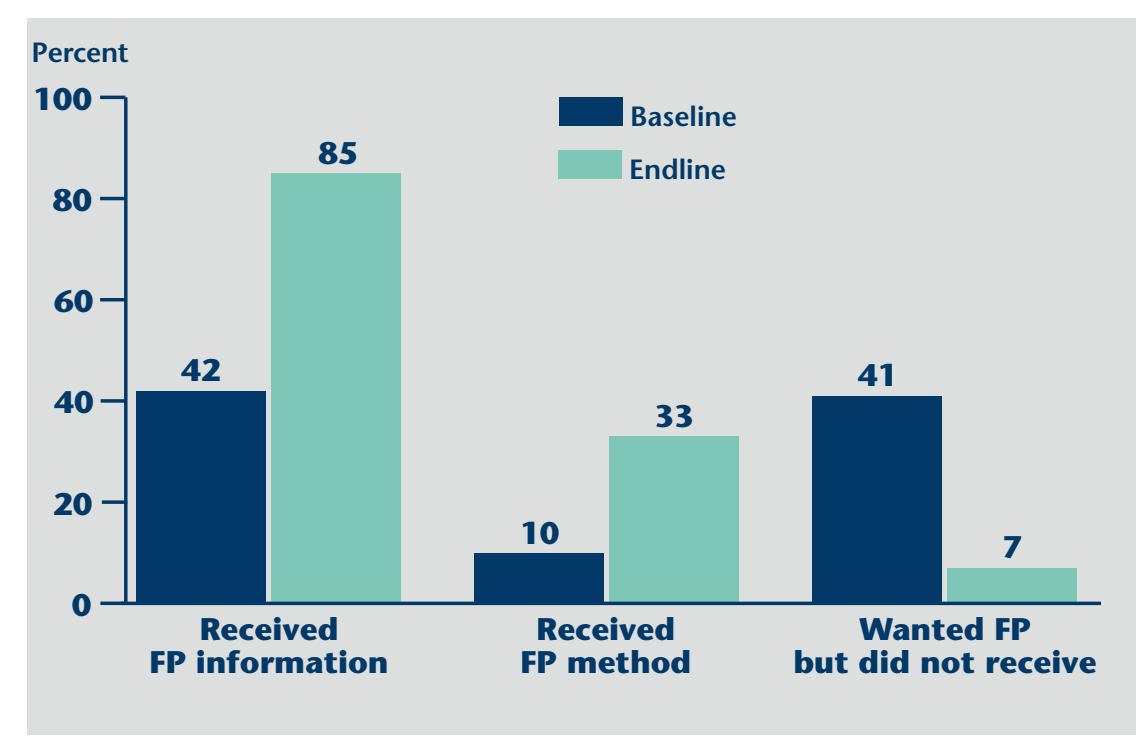

Source: Medina, Vernon, Mendoza, and Aguilar 2001. 
Figure 2.

\section{Proportion of women receiving information and counseling during the hospital stay and proportion receiving a method before hospital discharge}

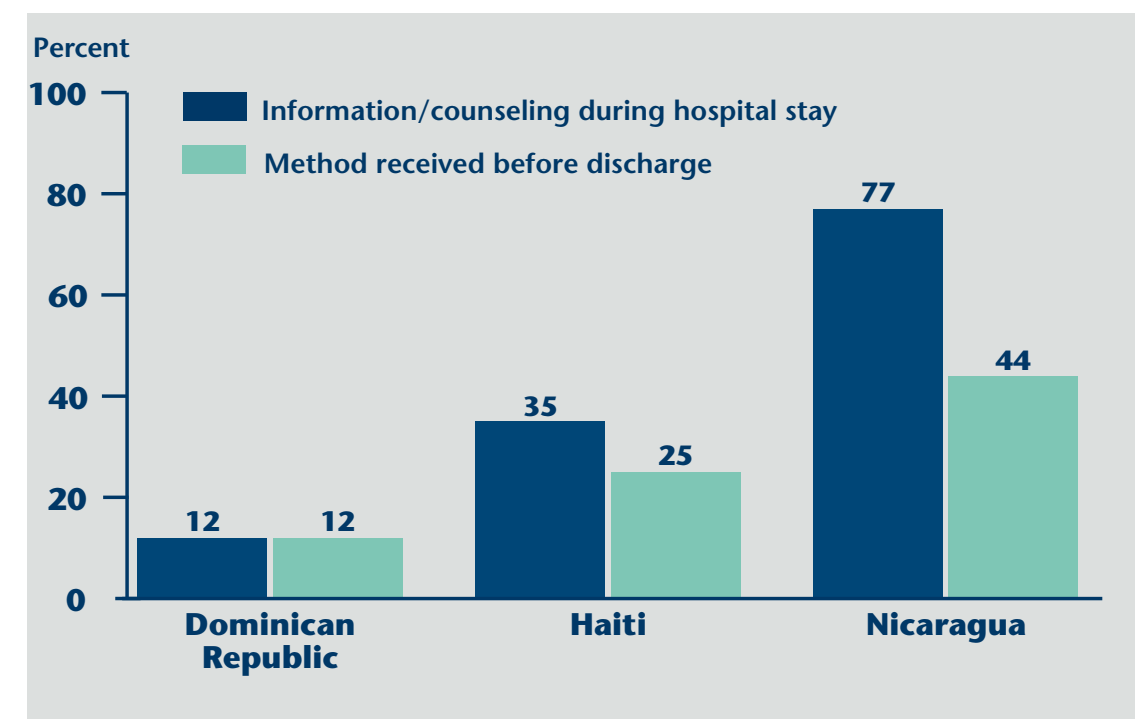

Sources: Quiterio et al. 2007; Rivero-Fuentes et al. 2007; Rivero-Fuentes, Vernon, Boulos, and Boulos 2007; Solís et al. 2007.

shows results from the combined analysis of diagnostic studies in three countries. Findings demonstrate a clear relationship between the degree to which women report being informed, counseled about, and offered methods during their hospital stay and the uptake of methods before discharge from the hospitals.

\section{Emphasize the 40th-day postpartum visit for mother and child}

Several projects streamlined service delivery for children and mothers by providing integrated infant and postpartum care services in a single visit on the 40th day (six weeks). In many countries this is a culturally significant day that signals the end of a woman's reclusive period following childbirth. A Ministry of Health (MOH) hospital in Tunisia tested scheduling a single visit for mothers and children on the 40th day postpartum. Of 9,240 women who gave birth at the hospital, 83 percent attended the postpartum visit, an increase of 10 percentage points over the previous year. Of the women who attended the postpartum visit, 56 percent accepted a family planning method.

The 40th-day clinic model was replicated by a Social Security Hospital (HSSI, in its Spanish acronym) in Honduras. This intervention involved linking the scheduled services for mothers and children and developing a streamlined information system requiring fewer data collection forms. Over a 15-month period, an average of 25 percent of all women delivering at the hospital received a contraceptive method before discharge. The linked mother-child services decreased the number of visits needed, so the HSSI was able to increase the rate of mothers returning for postnatal care at 40 days from less than 10 percent to 40 percent, and half (51\%) of these women accepted a contraceptive method during this visit. Thus, by adding a second opportunity to choose a method at the 40th-day clinic, the HSSI provided contraceptive methods to an additional 20 percent of all women who had delivered at the hospital, to achieve a total of 45 percent of women starting family planning use in the first six weeks (Vernon, Lopez-Canales, Cárcamo, and Galindo 1993).

In both the Tunisia and Honduras studies, pediatricians provided the children's services, and gynecologists or general physicians provided care for mothers. Administrative barriers prevented both providers from delivering services in the same clinic, so an internal referral system (functional integration) was developed to streamline services (Vernon, Lopez-Canales, Cárcamo, and Galindo 1993). In health outlets with general practitioners, nurses, or paramedical providers, this would not be a problem because the same staff member could provide the services to both mothers and children. 
However, no single postpartum visit addresses all of women's contraceptive or reproductive health needs. Programs should encourage multiple visits throughout the postnatal period-in the days following delivery, at six weeks, at the sixmonth transition from breastfeeding or LAM, and through the first 12 months-and ensure that each woman's contraceptive needs are addressed at the appropriate time.

\section{In-reach approaches}

Because women are less likely to seek postpartum care than other services—such as immunization or well-baby services-some providers designed a protocol of services for women in the postpartum period who visit the clinic for any reason. In one example of this "opportunistic" approach, the Guatemalan $\mathrm{MOH}$ designed a strategy to systematically identify women in the postpartum period among all women visiting the clinic for any reason and to offer them a package of reproductive health and well-baby care services. In the intervention group, the proportion of women starting to use a method at six weeks increased from 3 percent to 15 percent, whereas in the nonequivalent comparison group it remained at 10 percent, suggesting that the intervention was effective (see Table 1).

Table 1.

\section{Percentage of postpartum women using contraception in control and intervention groups, Guatemala}

\begin{tabular}{lcccc} 
& \multicolumn{2}{c}{ Experimental } & \multicolumn{2}{c}{ Control } \\
& Baseline & Endline & Baseline & Endline \\
\hline$>40$ days & 3 & 15 & 10 & 10 \\
90 days & 18 & 25 & 20 & 14
\end{tabular}

Source: Jacobs, Brambila, and Vernon 2002.

Researchers in Togo tested a similar in-reach strategy. Providers of children's immunizations gave mothers a 30-second referral message for family planning services during their visit. The intervention increased awareness of available family planning services by 18 percent and increased the mean number of monthly family planning clients by 58 percent (Huntington and Aplogan 1994).

\section{Focus on strengthening key provider behaviors}

Several Population Council projects designed a more comprehensive protocol for the integral care of mothers and children and trained service providers to focus on key behaviors to increase the overall quality of care. Projects in sub-Saharan Africa (Kenya, 1 Lesotho, and Swaziland ${ }^{2}$ )

1 The Kenya project was a partnership between FRONTIERS and ACCESS-FP.

2 The Swaziland project was implemented by the Population Council's USAID-funded Horizons Project. designed comprehensive orientation packages and protocols for the integrated postpartum care of mothers and infants. Service providers were specifically trained to focus on key behaviors to increase the overall quality of postnatal care, which included assessing mothers and infants and providing family planning counseling, services, and methods. Job aids were produced to help them implement the new guidelines.

Improvements occurred in all three countries in terms of giving immunizations to the infants and providing key information on return to fertility, family planning, and breastfeeding. Following training in Swaziland, for instance, the quality of care indices increased significantly for maternal health services (from a mean of 1.8 to 10.9 on a 25-point scale), and for newborn health care (from 2.9 to 10.8 on 
a 22-point scale) (Warren et al. 2008). In observed sessions with postpartum women six weeks post-delivery, family planning counseling and services also improved in Swaziland, and significant improvements in family planning services also were observed in Kenya (see Table 2).

\section{Focus training on essential knowledge and practices}

The results shown in Table 2 indicate that the training was effective. However, the overall quality of services remains low.
This hightlights the importance of providing continuing followup training, given the large number of items that providers need to learn to offer quality postpartum services. In the three projects, providers' knowledge and practices regarding key components (e.g., managing sepsis and hemorrhage) did not change (Mwangi, Warren, Koskei, and Blanchard 2008; Warren et al. 2008; Warren, Tšukulu, Phafoli, and Majara 2008). Health managers need to identify the essential knowledge points and skills that providers need to

Table 2.

\section{Family planning integrated into postnatal care services among postpartum women at six weeks after delivery, Kenya}

\begin{tabular}{|c|c|c|}
\hline $\begin{array}{c}\text { Contraceptive counseling and } \\
\text { services }\end{array}$ & $\begin{array}{c}\text { Baseline } \\
\begin{array}{c}(n=68) \\
\%\end{array}\end{array}$ & $\begin{array}{c}\text { Endline } \\
(\mathbf{n}=70) \\
\%\end{array}$ \\
\hline Return to fertility* & 32 & 67 \\
\hline Return to sexual activity* & 16 & 45 \\
\hline Advising on $\mathrm{FP}^{*}$ & 12 & 40 \\
\hline Two or more methods* & 36 & 67 \\
\hline $\begin{array}{l}\text { Healthy timing and spacing of } \\
\text { pregnancies* }\end{array}$ & 7 & 40 \\
\hline $\begin{array}{l}\text { Health benefits of FP for mother } \\
\text { and baby* }\end{array}$ & 8 & 33 \\
\hline $\begin{array}{l}\text { Provider asks which method is } \\
\text { preferred* }\end{array}$ & 40 & 82 \\
\hline Client receives preferred method* & 39 & 81 \\
\hline Total index score $(0-8)^{*}$ & 1.64 & 4.19 \\
\hline
\end{tabular}

${ }^{*} \mathrm{p}<0.01$

Source: Mwangi, Warren, Koskei, and Blanchard 2008.

master in a first stage and then provide training and supervision through an extended period of time until the full curricula is internalized. Job aids should be prepared to help providers improve their performance, and continuous support should be provided through supervision-a key component of quality care that is little discussed.

\section{Community-based care}

There is a critical need for skilled care in noninstitutional settings. An analysis of Demographic Health Surveys (DHS) data from 30 countries showed that half of births take place outside of health care facilities (Fort, Kothari, and Abderrahim 2006). Community-based interventions may hold considerable potential for enhancing mother and child health in remote settings where access to clinics is difficult.

\section{Several Population Council} projects tested community-based postpartum contraceptive interventions. In Uttar Pradesh, India, the Health Department tested a community-based approach to increase access to postpartum family planning and birth-spacing information and services. The intervention focused on

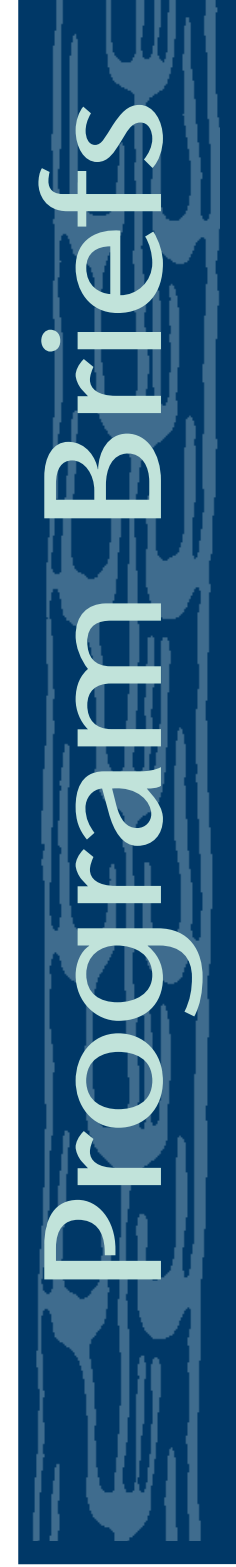




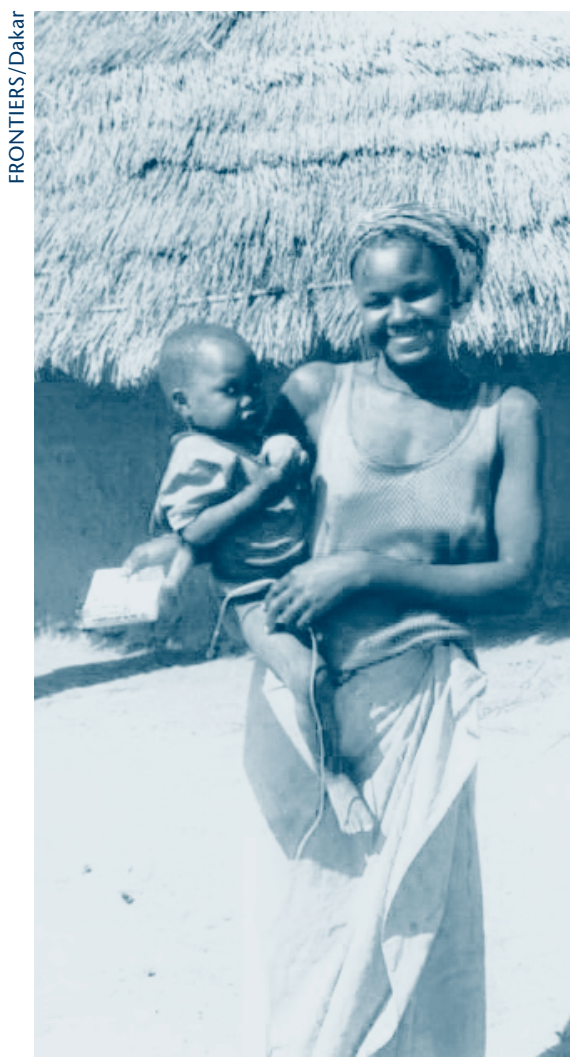

A young mother and family planning user in Senegal

young couples and low-parity women because these women often have limited access to family planning information, and cultural values favor short birth intervals. Village-level workers were trained to give messages on optimal birth spacing, LAM, and postpartum contraception to low-parity women and distribute printed materials at village meetings. This approach resulted in substantial increases in knowledge of LAM and other contra- ceptive methods. The proportion of women who used LAM and made a transition to other contraceptive methods at six months increased from 0 percent to 22 percent, and use of methods at 10 months postpartum was 63 percent in the experimental group, compared with 32 percent in control areas (Khan, Sebastian, and Idnani 2008).

In Kenya, FRONTIERS supported the scale-up of a community midwifery strategy aimed at increasing access to skilled care from pregnancy through the postpartum period. Community midwives (CMs) attend women who deliver at home, and they provide services for care during pregnancy, labor and childbirth, and the postpartum period, including family planning. The midwife visits the client at home two or three times during the first week after delivery and provides family planning counseling, short-term methods (injectables, combined oral contraceptives, and condoms), and referral for female sterilization. The community midwives assisted at 10 percent to 16 percent of births in four districts and, through referrals, increased women's use of facilities for birth. In addition, the community midwives provided family planning methods, in some districts serving as a significant source of methods ( $20 \%$ of the condoms provided in ButereMumias district, and 11\% of the Depo-Provera injections and 19\% of combined oral contraceptives in Mt. Elgon).

\section{Home visits}

Several studies tested the effect of home visits by clinic-based staff on women's use of postpartum care, especially for lowparity women, who usually have a great need for information, support, and services. In Egypt, guidelines mandated five home visits to low-parity women in the first 40 days. These visits were used to reinforce health messages and encourage a 40th-day clinic visit, during which mothers and children received comprehensive, integrated care. At 10-11 months after delivery, 48 percent of mothers in the target group were using a contraceptive method, compared to 31 percent in a control group where no intervention took place. Increased willingness to delay the next pregnancy three years or more also was observed in the intervention groups (Abdel-Tawab, Loza, and Zaki 2008).

In the West Bank and Gaza, community health workers normally conduct a home visit within three days of a delivery. The Pilot Health Project tested the effect of a second home visit, between 33 and 38 days post-delivery, on the attendance of low-parity women at the 40th-day postpartum clinic. In the intervention group, 49 percent of women attended the services, compared to 36 percent in the comparison group who 
received only one visit closely following their delivery. The second visit also was associated with increased husband-wife communication regarding the timing of the next pregnancy, but not with improvement in other outcomes, including use of family planning methods at six months; the number of visits to the health center in the first six postpartum months; and knowledge of breastfeeding, weaning, and immunizations. Thus, the second visit does not appear to add impact (CDPHC 2003).

\section{Approaches with limited success}

Studies show that two approaches-family planning counseling during antenatal care and LAM — have had limited impacts on subsequent use of contraceptives.

\section{Contraceptive education during antenatal care}

The evidence on providing family planning information during antenatal care is mixed. A retrospective study using DHS data from Bolivia, Egypt, Thailand, and Mexico found a relationship between attendance to antenatal care and subsequent use of contraceptives, though it is not clear whether or not the services included family planning counseling (Zerai and Tsui

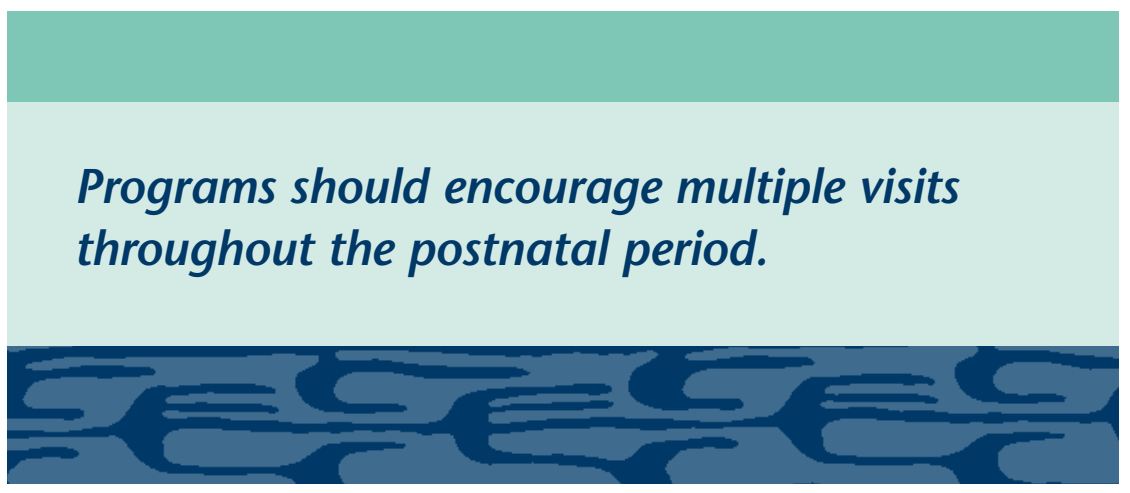

2001). A randomized prospective study conducted in antenatal clinics in China, Scotland, and South Africa, in which some women received information on contraception in antenatal care and some did not, found no differences in subsequent contraceptive use (Smith et al. 2002). In Nicaragua, the Dominican Republic, and Haiti, information on antenatal care was not found to influence subsequent contraceptive use, but it did increase the likelihood that women would use postpartum care; and information during the hospital stay or during postnatal care consultations increased the likelihood of family planning use (Rivero-Fuentes 2008).

Nevertheless, providing key essential messages at all contact points during the maternal cycle will increase the proportion of women who receive the information and are able to make an informed decision. If anything, the research results suggest not to eliminate information at antenatal consultations, but rather to improve the content of information given during the hospital stay and postnatal care visits.
Several programs in Mexico and Honduras with strong links between inpatient and outpatient services have established mechanisms to allow women receiving family planning counseling during antenatal care to choose a method that can be delivered immediately postpartum (Cardona et al. 1997; Vernon, Lopez-Canales, Cárcamo, and Galindo 1993). The choice is recorded in the medical history that is referred along with the patient. The method desired is confirmed at the maternity center, and the method is provided immediately postpartum or at 40 days postpartum. Wherever feasible, programs should implement this type of referral system, not only for delivery of methods at these times but also for women who want to adopt a method at a later stage. 


\section{Breastfeeding education and use of LAM}

Research has clearly established the links among breastfeeding (including LAM), infant health, and contraception. Exclusive breastfeeding for up to six months has been shown to protect infants from HIV (Iliff et al. 2005). Properly practiced, LAM has been shown to be 98 percent effective in preventing pregnancy (WHO/RHR and CCP 2007).

Yet OR projects seeking to increase the use of LAM and subsequent methods had mixed results. A FRONTIERS study in Kazakhstan, in which women in intervention groups were counseled on LAM use, revealed no difference in LAM use between intervention and control hospitals at six months (Tazhibayev et al. 2004). Also, while half the women in intervention hospitals said that they planned to use LAM, significantly fewer knew the three essential elements of LAM (exclusive breastfeeding, during amenorrhea, first six months postpartum). Another study found similar results but reported improved child health outcomes (Alvarado et al. 1999), while still another study reported greater use of contraceptives at 12 months by LAM users than by non-LAM users (e.g., Hardy et al. 1998).

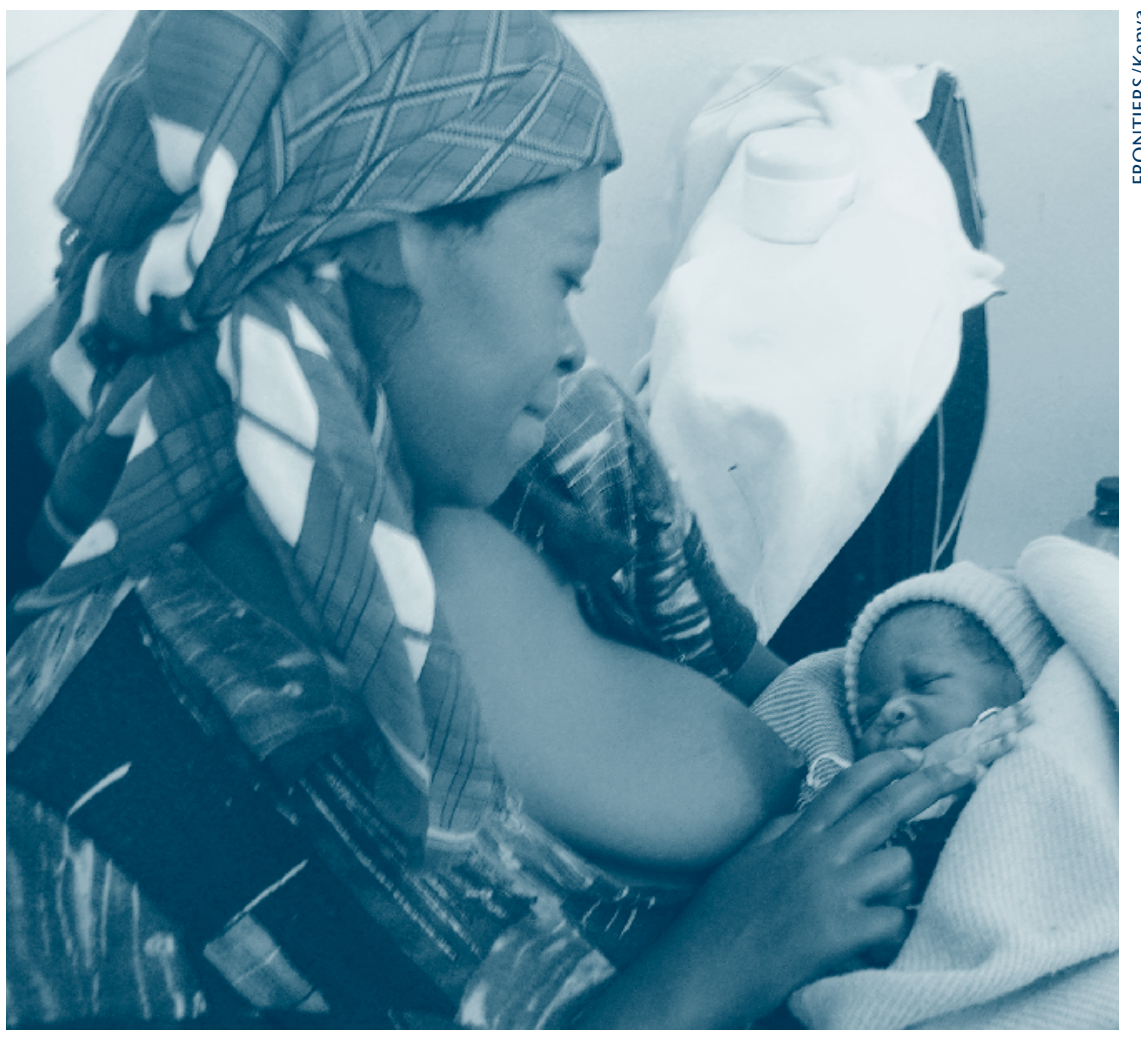

A mother in Lesotho prepares to breastfeed her baby.

Several studies show that weak foundations for LAM use-in terms of policy support, knowledge, and practice-limit the effectiveness of LAM promotion. The diagnostic studies in the Dominican Republic, Haiti, and Nicaragua, as well as the studies in Lesotho and Swaziland, show that only a minority of providers and clients clearly understand the connections among breastfeeding, the return of menses, and fertility. Other studies corroborate these findings. A study in Bangladesh showed that poor urban women are aware of a diminished risk for pregnancy during amenorrhea, but most are unaware of its association with breastfeeding (Salway and Nurani 1998). In Jordan, although onethird of mothers who had a child aged 13-24 months reported that they relied on breastfeeding as a contraceptive during the first six months postpartum, only 7 percent knew the three criteria needed to use LAM-although those who did know the criteria were more likely to use other methods at six months (Bongiovanni et al. 2005). A possible approach for breastfeeding or LAM education would be as a gateway to use of modern methods, or as a way of addressing women's concerns about infant survival and on using LAM as a bridge to other methods (McKaig and Chase [eds.] 2007). 
Ensuring quality in postpartum family planning services

OR studies have revealed important practices for ensuring quality of care in delivery of methods and provider interactions with clients who have special needs.

\section{Informed consent for sterilization and the IUD}

Several projects in LAC found that a small percentage of providers does not always fully comply with informed consent procedures for clinical methods in the immediate postpartum period. They tend to consider informed consent as a document to be signed rather than a process to help the client make a decision; thus they may ask for the client's signature without reading the form and without the presence of witnesses. In some cases, although providers believed that they had followed procedures fully, clients did not recall having given their consent for a method they received. Analysis of these cases showed that clients did not understand the questions or signed the document without understanding the implications. In some cases, the decision had been made by the husband or by the provider for medical reasons (Cardona et al. 1997; León 1999; León and García 2001).
Informed consent should be obtained after fully counseling the client. Wherever possible, women receiving antenatal care should be given counseling and offered a choice of a method for use immediately after delivery, with an opportunity to ratify the decision at the hospital, as is done in Honduras and Mexico. Providers should avoid introducing obstructive requirements, such as signing multiple forms, requesting the husband's consent, or requiring a reflection period of several days, which can act as barriers to women's choice (Vernon, Lopez-Canales, Cárcamo, and Galindo 1993).

To highlight the importance of informed consent, programs should establish a means of reporting violations and disseminate information about the right to choose a contraceptive method and the mechanisms available for violations of this right (Santos, Llaguno, and Vernon 1999).

\section{Postpartum family plan- ning in high-HIV settings}

The family planning needs of postpartum women, especially HIV-positive women, often are not addressed, even in programs to prevent the transmission of HIV from mother to child (Rutenberg and Baek 2004). Yet reducing unwanted pregnancies in HIV-positive women is a key component of the World Health Organization (WHO) comprehensive PMTCT strategy, with the potential of preventing an estimated 120,000 HIV-positive births (WHO 2004; Richey and Setty 2007). Prevention of pregnancies among HIV-positive women has been described as the "best kept secret in PMTCT" (Reynolds and Wilcher 2006).

In a number of countries, the national family planning training program needs to be strengthened, and more providers need to be updated on technical family planning skills for providing services to HIVpositive mothers. At the time of the 2004 DHS in Lesotho, for example, the national HIV policy made no reference to family planning at all (Strachan et al. 2004). A situation analysis in Haiti showed that in help centers half the providers for all mother and child health services had no training on family planning
The family planning needs of postpartum women, especially HIV-positive women, often are not addressed, even in programs to prevent the transmission of HIV from mother to child.

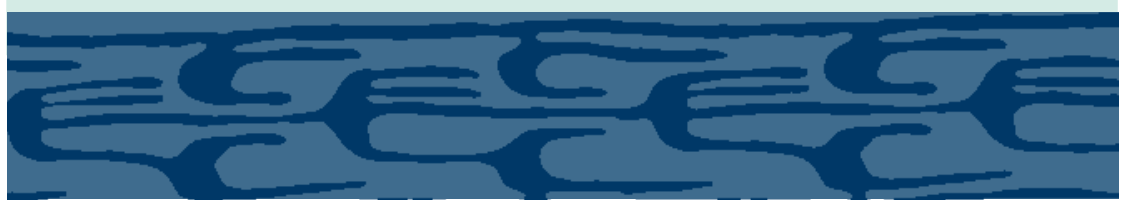


options for HIV-positive women (Rivero-Fuentes 2008). Because recommendations regarding the care of HIV-positive women and the PMTC of HIV change constantly, frequent workshops that update providers' knowledge are necessary.

The FRONTIERS projects in Kenya, Lesotho, and Swaziland, where rates of HIV are very high, tested the feasibility and effects of a package of services for postpartum women integrating improved postnatal care, HIV services, and family planning. The findings documented overall improvements in quality of care, including improved family planning counseling, with increased use of contraception in Kenya and Swaziland. While improvements did not achieve universal coverage, the three studies demonstrated that it is feasible to provide comprehensive services to postpartum women and their infants in high-HIV areas (Mwangi, Warren, Koskei, and Blanchard 2008; Warren et al. 2008; Warren, Tšukulu, Phafoli, and Majara 2008).

\section{Men's participation in family planning}

Several projects have sought to assess the impact of involving the male partner in antenatal and postpartum care. The results suggest that while male involvement has positive health outcomes, the overall impact of this type of intervention varies according to the degree to which men actually attend the meet-

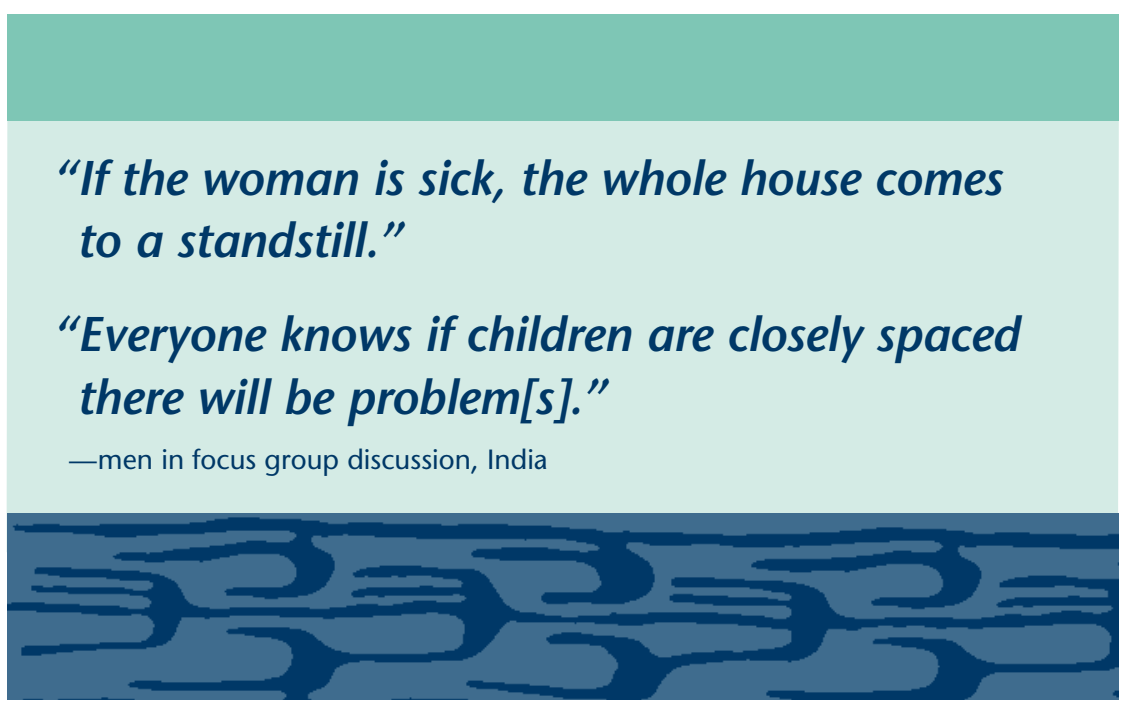

ings and sessions, which in turn seems to depend largely on local social conditions.

FRONTIERS projects in India and South Africa tested the effects of inviting male partners to one antenatal and one postnatal care visit on the uptake of contraception and the prevention of sexually transmitted infections. In South Africa's KwaZulu Natal province, where most $\mathrm{MOH}$ clients are not married or do not live with the father of the baby, only 27 percent of partners attended at least one of the joint counseling sessions, and few differences were observed between the experimental and the control groups (Kunene et al. 2004).

The same intervention took place in India, where clinics were managed by an insurance corporation that serves state workers and where nearly all clients were in a stable marriage. In this setting, almost half of male partners attended at least one joint counseling session on antenatal or postpartum care (43\% and $47 \%$, respectively). Providers in the India intervention group were more likely to provide information on a large range of education topics relative to those in the control group (although except for family planning, less than half the clients received information on any single topic). As a consequence, compared to the control group, the women attending the intervention group clinics had higher knowledge of LAM and danger signs, higher contraceptive use at six to nine months after delivery (see Table 3 ), and better interspousal communications on the baby's health, family planning, and breastfeeding.

Other studies show that while many men cannot or will not accompany their wives to postnatal visits, providing educational material for wives to share can increase men's knowledge of contraception. Studies in Egypt 
and India (Abdel-Tawab, Loza, and Zaki 2008; Khan, Sebastian, and Idnani 2008) showed that few men attended seminars or group meetings about using family planning for healthy timing between pregnancies. In the Egypt study, focus group discussions showed that men's knowledge of family planning appeared to be similar in the intervention and control groups. The men reported that the messages on family planning had "trickled down" to them, either because they had discussed it with men who attended the seminars, or because their wives had showed them informational leaflets or flyers on family planning.

In the India study, women received a booklet on healthy spacing of pregnancies. The booklet used stories to illustrate the benefits ensuing from healthy spacing of pregnancies, and described a range of contraceptive methods. When wives shared the brochure with their husbands, the likelihood of interspousal discussion of contraception was much higher in the intervention group than in the control group (61\% versus $41 \%)$. Men's knowledge of contraception also increased significantly in the intervention group. Analysis showed that the likelihood (odds ratio) of postpartum contraceptive use was four to seven times higher when husbands and wives discussed family planning than when no such discussion took place.
Table 3.

\section{India: Use of family planning methods at six months postpartum}

\begin{tabular}{lcccc} 
& \multicolumn{2}{c}{ Experimental (\%) } & \multicolumn{2}{c|}{ Control (\%) } \\
& $\begin{array}{l}\text { Women } \\
\mathrm{n}=289\end{array}$ & $\begin{array}{c}\text { Men } \\
\mathrm{n}=293\end{array}$ & $\begin{array}{c}\text { Women } \\
\mathrm{n}=269\end{array}$ & $\begin{array}{c}\text { Men } \\
\mathrm{n}=270\end{array}$ \\
$\begin{array}{l}\text { Currently using any } \\
\text { FP method }\end{array}$ & $59^{*}$ & $65^{*}$ & 45 & 48 \\
Pills & 9 & 8 & 7 & 6 \\
IUD & 8 & 7 & 8 & 8 \\
Condoms & 66 & 71 & 66 & 71 \\
Female sterilization & 11 & 10 & 15 & 13
\end{tabular}

${ }^{*} \mathrm{p}<0.05$

Source: Varkey et al. 2004

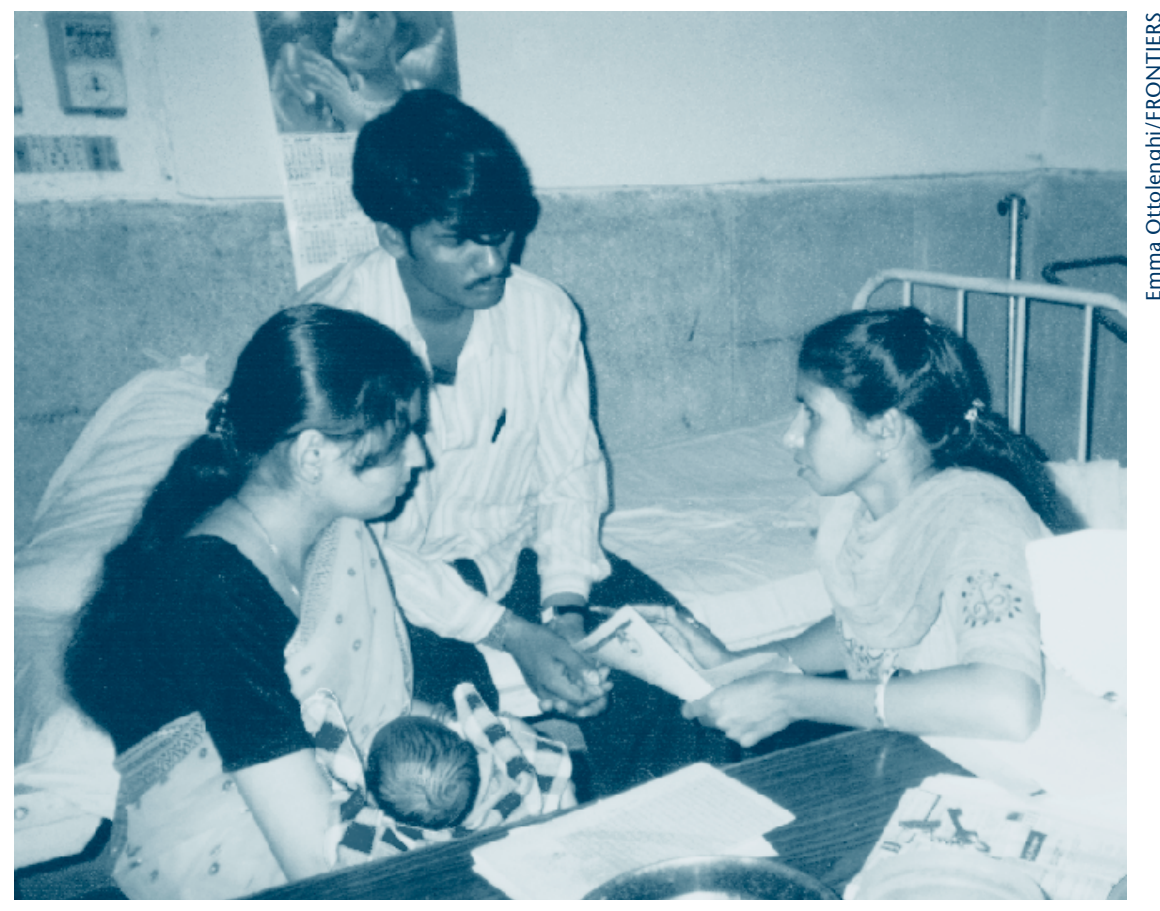

A couple in India discuss postpartum care. 


\section{Conclusions}

Research has shown that postpartum family planning can contribute significantly to efforts to meet women's fertility goals, prevent unwanted pregnancies, and protect mothers and children in areas of high HIV prevalence. Studies throughout the developing world identified promising practices, including providing a range of contraceptive methods, offering contraceptive methods and information on fertility throughout the maternal cycle, and emphasizing provider training and compe- tence in key skills. Additionally, research has shown not only that family planning services can be integrated with other services, including postpartum care, well-baby services, and HIV prevention and care services, but also that integration can enhance the effectiveness of programs and increase their benefit to clients.

Clearly there are gaps in knowledge needing additional research, such as studies on community-based delivery of postpartum family planning and approaches for improving supervision of care. In many countries, policies governing contraception in the postpartum period remain weak or nonexistent. It will take a concerted and sustained effort to fill the gaps in knowledge, practices, and policies needed to address women's unmet needs for family planning in the first year following delivery. However, this effort is critical to protect the well-being of mothers, infants, and families.

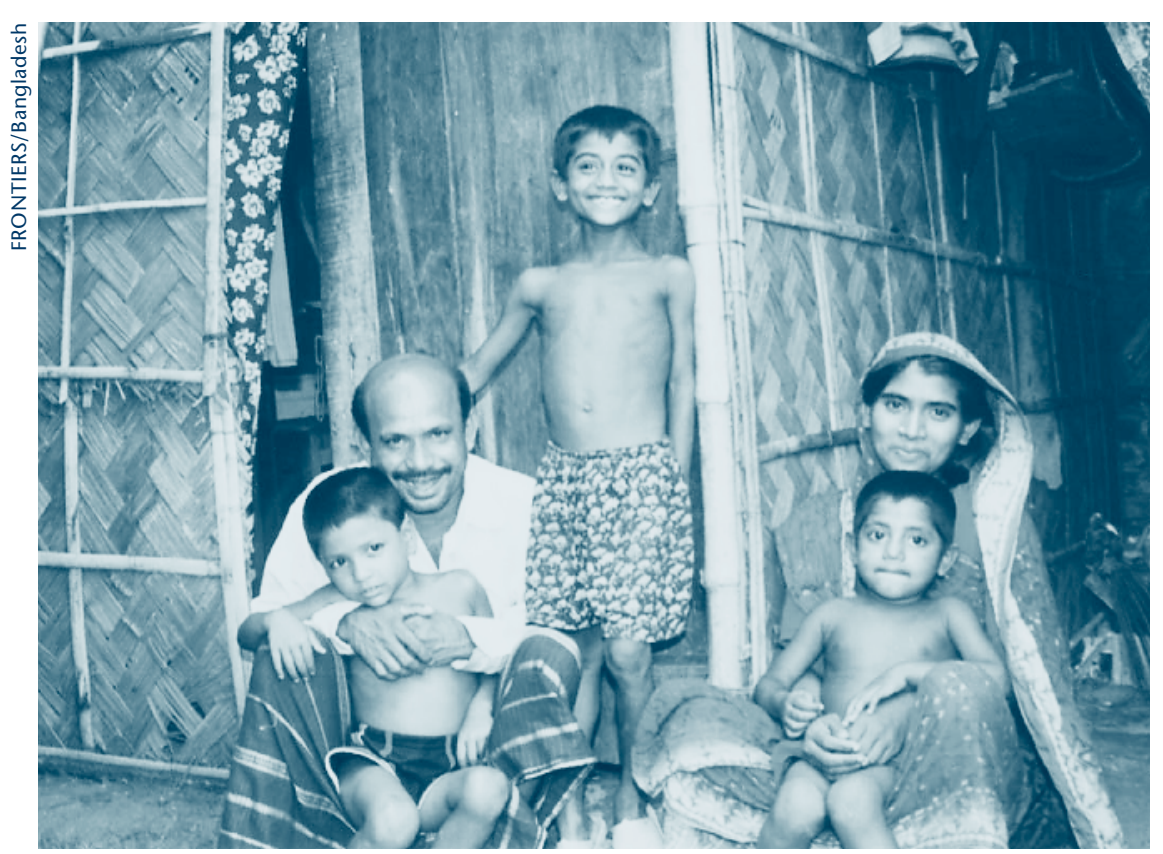

Family in Bangladesh. 


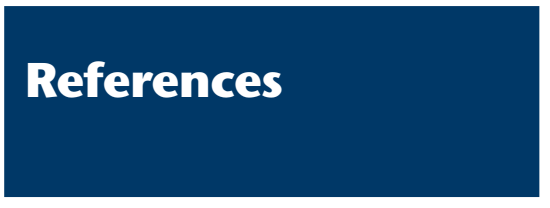

Abdel-Tawab et al. 2006.

"Helping Egyptian women achieve optimal birth spacing intervals through maximizing opportunities in antenatal and postpartum care," FRONTIERS Research Update No. 9. Cairo: Population Council.

Abdel-Tawab, Nahla, Sarah Loza, and Amal Zaki. 2008. "Helping women achieve optimal birth spacing intervals: Testing two models of providing birth spacing messages to pregnant and postpartum women," FRONTIERS Final Report (in press). Washington, DC: Population Council.

Adeyemi, Adbanjo B. et al. 2005. "The unmet need for contraception among Nigerian women in the first year postpartum," European Journal of Contraception and Reproductive Health Care 10(4): 229-234.

Alvarado, Reynaldo et al. 1999. "Integrated maternal and infant health care in the postpartum period in a poor neighborhood in Santiago, Chile," Studies in Family Planning 30(2): 133-141.

Blanc, Ann K., Sian L. Curtis, and Trevor N. Croft. 2002. "Monitoring contraceptive continuation: Links to fertility outcomes and quality of care," Studies in Family Planning 33(2): 127-140.
Bongiovanni, Annette et al. 2005. "Promoting the lactation amenorrhea method (LAM) in Jordan increases modern contraception use in the extended postpartum period," Linkages Final Report. Washington, DC: Academy for Educational Development.

Brambila, Carlos, Werner Figueroa, and Bertha Taracena. 2001. "Situational analysis of post-obstetric event services in public hospitals in Guatemala," FRONTIERS Final Report. Washington, DC: Population Council.

Bulut, Aysen and Janet MolzanTuran. 1995. "Postpartum family planning and health needs of women of low income in Istanbul," Studies in Family Planning 26(2): 88-100.

Campbell, O.M. and W.J. Graham. 2006. "Strategies for reducing maternal mortality: getting on with what works," Lancet 368(9543): 1284-1299.

Cárcamo, Arnulfo, José R. López-Canales, Nancy Murray, and John Townsend. 1990.

"Reproductive risk: A strategy to improve family planning services at the Honduran Social Security Institute," INOPAL II Operations Research Final Report. Tegucigalpa and New York: Instituto Hondureño de Seguridad Social (IHSS) and Population Council.

Cardona, Arturo et al. 1997.

"Informed choice of contraception after an obstetric event," INOPAL III Operations Research Final Report. Mexico City: Population Council.
Center for Development in Primary Health Care (CDPHC), Al Quds University. 2003. "Improving postpartum care among low-parity mothers in Palestine," FRONTIERS Final Report. Washington, DC: Population Council.

Cleland, S. et al. 2006. "Family planning: the unfinished agenda," Lancet 368(9549): 1810-1827.

Coeytaux, Francine. 1989. "Celebrating mother and child on the fortieth day. The Sfax, Tunisia, postpartum program," Quality/Calidad/Qualité No. 1. New York: Population Council.

Foreit, Karen G., James R. Foreit, Gloria Lagos, and Alfredo Guzman. 1993. "Effectiveness and cost-effectiveness of postpartum IUD insertion in Lima, Peru," International Family Planning Perspectives 19(1): 19-24, 33.

Fort, Alfredo L., Monica T. Kothari, and Noureddine Abderrahim. 2006. "Postpartum care: Levels and determinants in developing countries," DHS Comparative Reports No. 15. Calverton, Maryland: Macro International, Inc.

Hardy, Ellen et al. 1998.

"Contraceptive use and pregnancy before and after introducing lactational amenorrhea (LAM) in a postpartum program," Advances in Contraception 14(1): 59-68.

Huntington, Dale and Aristide Aplogan. 1994. "The integration of family planning and childhood immunization services in Togo," Studies in Family Planning 25(3): 176-183. 
Iliff et al. 2005. "Early exclusive breastfeeding reduces the risk of postnatal HIV-1 transmission and increases HIV-free survival," AIDS 19(7): 699-708.

Jacobs, Erika, Carlos Brambila, and Ricardo Vernon. 2002.

"Reproductive health care in the postnatal period in Guatemala," FRONTIERS Final Report.

Washington, DC: Population Council.

Khan, M.E. 2003. "Situational analysis of the postpartum programme in India," The National Medical Journal of India 16(Supplement 2): 28-34.

Khan, M.E., Mary Sebastian, and Rukma Idnani. 2008. "Promoting optimal inter-pregancy intervals in India through integrated public delivery systems," FRONTIERS Final Report. Washington, DC: Population Council.

Kunene, Busi et al. 2004. "Involving men in maternity care: South Africa," FRONTIERS Final Report. Washington, DC: Population Council.

León, Federico. 1999. "Providers' compliance with quality of care norms," FRONTIERS Final Report. Washington, DC: Population Council.

León, Federico and Ingeborg García. 2001. "Peru 2000: Compliance with Ministry of Health norms," FRONTIERS Final Report. Washington, DC: Population Council.
León-Cava, Natalia, Chessa Lutter, Jay Ross, and Luann Martin. 2002. Quantifying the Benefits of Breastfeeding. A Summary of the Evidence. Washington, DC: Pan American Health Office (PAHO).

McKaig, Catharine and Rebecca Chase (eds.). 2007. Postpartum Family Planning Technical Consultation-Meeting Report. Baltimore: JHPIEGO.

Medina, Ruth, Ricardo Vernon, Irma Mendoza, and Claudia Aguilar. 2001. "Expansion of postpartum and postabortion contraception in Honduras," FRONTIERS Final Report.

Washington, DC: Population Council.

Mwangi, Annie, Charlotte Warren, Nancy Koskei, and Holly Blanchard. 2008. "Strengthening postnatal care and postpartum family planning in Kenya," FRONTIERS Final Report. Washington, DC: Population Council and ACCESS - FP.

Mwangi, Annie, Douglas Waswa, and Charlotte Warren. 2008.

"Taking critical services to the home: Scaling up home based maternal and postnatal care, including family planning, through community midwifery," FRONTIERS Final Report. Washington, DC: Population Council.
Paiva, Vera, M. R. Latorre, N. Gravato, and R. Lacerda. 2002. "Sexualidade de mulheress vivendo com HIV/AIDS em São Paulo [Sexuality of women living with HIV/AIDS in São Paulo], Cadernos de Saude Pública 18(6): 1609-1620.

Population Council. 2008. "Promoting family planning during the postpartum period can increase contraceptive acceptance," OR Summary No. 74. Washington, DC: Population Council.

Quiterio, Gisela et al. 2007. "Dominican Republic: Diagnostic study of postpartum, postabortion and PMTCT contraceptive services," FRONTIERS Final Report. Washington, DC: Population Council.

Reynolds, H.W. and R. Wilcher. 2006. "Best kept secret in PMTCT: Contraception to avert unintended pregnancies," AIDSlink (97): 8-9.

Richey, C. and V. Setty. 2007. "Family planning choices for women with HIV," Population Reports, Series L, No. 15.

Baltimore: INFO Project, Johns Hopkins Bloomberg School of Public Health.

Rivero-Fuentes, Estela, Ricardo Vernon, Micaela Boulos, and Louis Marie Boulos. 2007. "Haiti: Situational analysis of the use of contraception in postpartum, postabortion and prevention of mother to child HIV transmission," FRONTIERS Final Report. Washington, DC: Population Council. 
Rivero-Fuentes, Estela. 2008. Original data analysis of data sets from the Dominican Republic, Haiti and Nicaragua used in Quiterio et al. 2007; RiveroFuentes, Vernon, Boulos, and Boulos 2007; and Solís et al. 2007.

Ross, John A. and William L. Winfrey. 2001. "Contraceptive use, intention to use and unmet need during the extended postpartum period," International Family Planning Perspectives 27(1): 20-27.

Rutenberg, Naomi and Carolyn Baek. 2004. "Review of field experiences: Integration of family planning and PMTCT services," Horizons Final Report Washington, DC: Population Council.

Salway, Sarah and Sufia Nurani. 1998. "Uptake of contraception during postpartum amenorrhoea: Understandings and preferences of poor, urban women in Bangladesh," Social Science and Medicine 47(7): 899-909.

Santos, Elsa, Silvia Llaguno, and Ricardo Vernon. 1999. "Mexico: protecting informed consent," FRONTIERS Final Report. Washington, DC: Population Council.

Smith, K.B. et al. 2002. "Is postpartum contraceptive advice given antenatally of value?" Contraception 65(3): 237-243.
Solís, Freddy et al. 2007.

"Situational analysis of the use of contraception in postpartum, postabortion and prevention of mother to child transmission (PMTCT) programs, Nicaragua," FRONTIERS Final Report. Washington, DC: Population Council.

Strachan, M. et al. 2004 "An analysis of family planning content in HIV/AIDS, VCT and PMTCT policies in 16 countries," Policy Working Papers Series No. 9. Washington, D.C: Futures Group International POLICY Project.

Tazhibayev, Shamil et al. 2004. "Promotion of lactation amenorrhea method intervention trial, Kazakhstan," FRONTIERS Final Report. Washington, DC: Population Council.

Varkey, Leila Caleb et al. 2004. "Involving men in maternity care in India," FRONTIERS Final Report. Washington, DC: Population Council.

Vernon, Ricardo, Jose Ruben Lopez-Canales, Jose Arnulfo Cárcamo, and Judith Galindo. 1993. "The impact of a perinatal reproductive health program in Honduras," International Family Planning Perspectives 19(3): 103-109.

Vernon, Ricardo, Jorge Solorzano, and Blanca Muñoz. 2007. "Introducing sustainable vasectomy services in Guatemala," International Family Planning Perspectives 33(4): 182-187.
Warren, Charlotte et al. 2008. "Repositioning postnatal care in a high HIV environment: Swaziland," Horizons Final Report. Washington, DC: Population Council.

Warren, Charlotte, Thato Tšukulu, Semakaleng Phafoli, and Bosielo Majara. 2008. "Extending prevention of mother-to-child transmission through postpartum family planning in Lesotho" FRONTIERS Final Report. Washington, DC: Population Council.

World Health Organization (WHO). 2004. Neonatal and Perinatal Mortality: Country, Regional and Global Estimates. Geneva: WHO.

World Health Organization Department of Reproductive Health and Research (WHO/RHR) and Johns Hopkins Bloomberg School of Public Health/ Center for Communication Programs (CCP), INFO Project. 2007. Family Planning: A Global Handbook for Providers. Baltimore and Geneva: CCP and WHO.

Zerai, Assatá and A.O. Tsui. 2001. "The relationship between antenatal care and subsequent modern contraceptive use in Bolivia, Egypt and Thailand," African Journal of Reproductive Health 5(2): 68-82. 
The Population Council conducts research worldwide to improve policies, programs, and products in three areas: HIV and AIDS; poverty, gender, and youth; and reproductive health.

The Frontiers in Reproductive Health Program (FRONTIERS) applies systematic research techniques to improve delivery of family planning and reproductive health services and influence related policies. FRONTIERS is funded by the U. S. Agency for International Development (USAID) and led by the Population Council in collaboration with Family Health International.

Frontiers in Reproductive Health Program (FRONTIERS) Population Council

4301 Connecticut Avenue, NW, Suite 280

Washington, DC 20008

Telephone: (202) 237-9400

Facsimile: (202) 237-8410

E-mail: publications@popcouncil.org

www.popcouncil.org/frontiers

This publication is made possible by the generous support of the American people through the United States Agency for International Development (USAID) under the terms of Cooperative Agreement No.

HRN-A-00-98-00012-00. The contents are the responsibility of the FRONTIERS Program and do not necessarily reflect the views of USAID or the United States Government.

(c) 2008 The Population Council, Inc.

This publication may be reproduced in whole or in part without permission of the Population Council provided full source citation is given and the reproduction is not for commercial purposes. 